\title{
Commentary: Management of mesenteric malperfusion syndrome in patients with type A aortic dissection: An unsettled issue
}

\author{
Pierpaolo Chivasso, $\mathrm{MD},{ }^{\mathrm{a}}$ and Vito Domenico Bruno, $\mathrm{MD}, \mathrm{PhD}^{\mathrm{b}}$ \\ From the a Department of Cardiac Surgery, Bristol Heart Institute, University Hospitals Bristol NHS Foundation \\ Trust, Bristol, United Kingdom; and ${ }^{\mathrm{b}}$ Department of Translational Health Science, Bristol Medical School, \\ University of Bristol, Bristol, United Kingdom. \\ Disclosures: Authors have nothing to disclose with regard to commercial support. \\ Received for publication Nov 23, 2018; accepted for publication Nov 26, 2018; available ahead of print May 18, \\ 2019. \\ Address for reprints: Vito Domenico Bruno, MD, PhD, Translational Health Sciences, Bristol Medical School, \\ University of Bristol, Research Floor Level 7, Bristol Royal Infirmary, Upper Maudlin St, BS2 8HW Bristol, \\ United Kingdom (E-mail: Vito.D.Bruno@bristol.ac.uk). \\ J Thorac Cardiovasc Surg 2019;158:690-1 \\ $0022-5223 / \$ 36.00$ \\ Copyright (c) 2018 by The American Association for Thoracic Surgery \\ https://doi.org/10.1016/j.jtcvs.2018.11.080
}

Acute type A aortic dissection (ATAAD) represents a lifethreatening disorder of the cardiovascular system. Aortic rupture and cardiac tamponade are the most common cause of death. ${ }^{1}$ Emergency surgery on the ascending aorta, with or without partial or total arch replacement, in most cases represents the only effective therapeutic option. Among all patients with ATAAD, those presenting with concomitant dissection-related severe malperfusion and consequent organ failure (malperfusion syndrome [MPS]) have a significantly increased mortality. ${ }^{2-7}$ In particular, mesenteric MPS has been reported to have a very poor prognosis, with an in-hospital mortality ranging from $60 \%$ to $75 \%$. The optimal management of patients with ATAAD who have MPS remains an unsettled issue. With advancements in the endovascular treatment of aortic pathology, however, we have more choices to treat mesenteric MPS percutaneously before central aortic repair, and this strategy appears to be associated with improved outcomes. ${ }^{6,7}$

In this issue of the Journal, Yang and colleagues ${ }^{8}$ present their decades-long work in trying to determine a better method to treat these patients at very high risk. From 1996 to 2017, they found 82 patients with ATAAD and mesenteric MPS, and they treated all of them with upfront interventional therapy before open aortic repair, in the hopes of resolving the visceral ischemia and its sequelae. To achieve endovascular reperfusion, a total of 113 fenestrations, 119 aortic stents, and 45 branch vessel stents were performed, together with a small number of branch vessel thrombolysis $(\mathrm{n}=3)$ and suction embolectomy $(\mathrm{n}=1)$ procedures. The operative mortality for the $82 \mathrm{pa}-$ tients with mesenteric MPS was significantly higher than that for those without mesenteric MPS (39\% vs 7.5\%; $P<.001$ ); for those who underwent both endovascular revascularization and open aortic repair, however, inhospital mortality and major postoperative complications

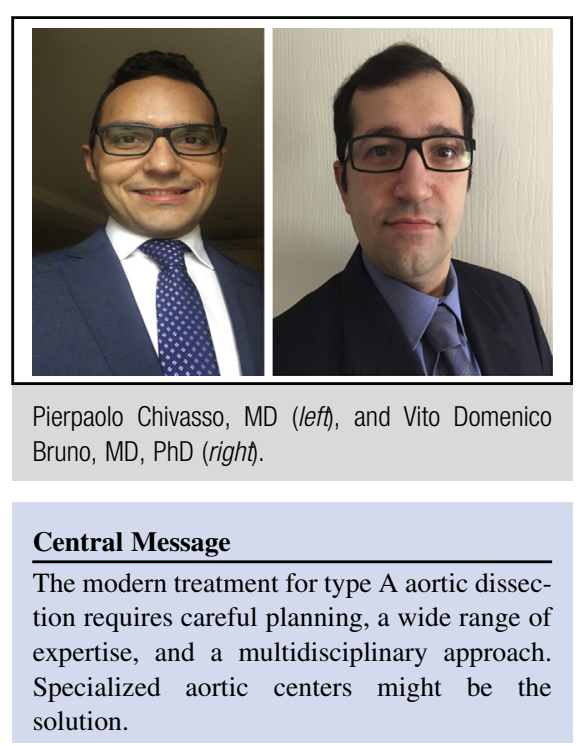

See Article page 675

were not significantly different from those of patients who had no mesenteric MPS ( $2.1 \%$ vs $7.7 \% ; P=.23)$, suggesting that the impact of this complication could potentially be eliminated if promptly and successfully treated. Another important finding of Yang and colleagues ${ }^{8}$ is represented by the recognition of stroke, bowel necrosis at laparotomy, and elevated serum lactate $(\geq 6 \mathrm{mmol} / \mathrm{L})$ as independent predictors of death from organ failure after resolution of malperfusion. This is further important information that can guide us in selecting which patient would benefit the most from a staged approach. Moreover, the long-term survival for patients with mesenteric MPS surviving to hospital discharge was similar to those without MPS, and mesenteric MPS at admission was no longer a risk factor after patients were successfully treated with endovascular fenestration or stenting and recovered from MPS (hazard ratio $=0.8 ; 95 \%$ confidence interval, $0.4-1.4 ; P=.37$ ).

Traditionally, the surgical community has emphasized the importance of emergency surgery, with the identification and resection of the primary tear and the replacement of the ascending or aortic arch to restore true-lumen perfusion. Given the presence of distal reentry tears, persistence of false-lumen flow, and potential for branch vessel involvement, however, the restoration of proximal truelumen inflow may not consistently address the problem 
of distal malperfusion. With the progress of endovascular techniques, some centers have implemented a strategy of central aortic operation after percutaneous end-organ blood flow restoration in patients presenting with significant mesenteric MPS. ${ }^{6,7}$ The results from the study of Yang and colleagues ${ }^{8}$ support once more the current idea that the treatment of patients with ATAAD should be based on their clinical presentation, rather than just focusing on repairing the ascending aorta in the quickest possible way. There is an increasing body of evidence suggesting worse operative mortality and both short- and long-term outcomes in patients with concomitant MPS (and particularly mesenteric MPS), so our practice should consider a more careful evaluation of the patients to stratify their risk, allow better decision making, and tailor the surgical strategies on the basis of the predicted individual risk. Endovascular treatment of the malperfusion, when performed as a staged procedure with open central aortic repair, appears to improve both short- and long-term outcomes. In patients with clinically significant mesenteric malperfusion at presentation, it certainly seems reasonable to start the surgical treatment with an endovascular reversal of the malperfusion, followed by central aortic repair ${ }^{7}$ if the patient is in clinically stable condition and there is no evidence of cardiac tamponade or aortic rupture. In this setting, the hybrid operating room assumes an important role, permitting the precise diagnosis of downstream malperfusion sites and allowing surgical or endovascular treatment without delay and at small risk to the patient. We believe that this is the way forward, and once again we endorse the crucial role of dedicated specialized aortic centers in the modern treatment of acute aortic syndromes. ${ }^{9}$ As already demonstrated by other studies, ${ }^{10}$ such centers provide better care for patients with ATAAD and have significantly improved outcomes in treating these very complex diseases.

\section{References}

1. Di Marco L, Leone A, Murana G, Castelli A, Alfonsi J, Di Bartolomeo R, et al Acute type A aortic dissection: rationale and outcomes of extensive repair of the arch and distal aorta. Int J Cardiol. 2018;267:145-9.

2. Di Eusanio M, Trimarchi S, Patel HJ, Hutchison S, Suzuki T, Peterson MD, et al Clinical presentation, management, and short-term outcome of patients with type A acute dissection complicated by mesenteric malperfusion: observations from the International registry of acute aortic dissection. J Thorac Cardiovasc Surg. 2013; 145:385-90.e1.

3. Augoustides JG, Geirsson A, Szeto WY, Walsh EK, Cornelius B, Pochettino A, et al. Observational study of mortality risk stratification by ischemic presentation in patients with acute type A aortic dissection: the Penn classification. Nat Clin Pract Cardiovasc Med. 2009;6:140-6.

4. Czerny M, Schoenhoff F, Etz C, Englberger L, Khaladj N, Zierer A, et al. The impact of pre-operative malperfusion on outcome in acute type A aortic dissection: results from the GERAADA registry. J Am Coll Cardiol. 2015;65: 2628-35.

5. Hofferberth SC, Newcomb AE, Yii MY, Yap KK, Boston RC, Nixon IK, et al. Hybrid proximal surgery plus adjunctive retrograde endovascular repair in acute DeBakey type I dissection: superior outcomes to conventional surgical repair. $J$ Thorac Cardiovasc Surg. 2013;145:349-54; discussion 354-5.

6. Geirsson A, Szeto WY, Pochettino A, McGarvey ML, Keane MG, Woo YJ, et al. Significance of malperfusion syndromes prior to contemporary surgical repair for acute type A dissection: outcomes and need for additional revascularizations. Eur J Cardiothorac Surg. 2007;32:255-62.

7. Perera NK, Galvin SD, Seevanayagam S, Matalanis G. Optimal management of acute type A aortic dissection with mesenteric malperfusion. Interact Cardiovasc Thorac Surg. 2014;19:290-4.

8. Yang B, Norton EL, Rosati CM, Wu X, Kim KM, Khaja MS, et al. Managing patients with acute type A aortic dissection and mesenteric malperfusion syndrome: a 20-year experience. J Thorac Cardiovasc Surg. 2019;158: 675-87.e4.

9. Chivasso P, Bruno VD. Open versus clamp-on distal anastomosis techniques in acute type A aortic dissection: the ship has already left the port. J Thorac Cardiovasc Surg. 2019;157:1761-2.

10. Mariscalco G, Maselli D, Zanobini M, Ahmed A, Bruno VD, Benedetto U, et al Aortic centres should represent the standard of care for acute aortic syndrome. Eur J Prev Cardiol. 2018;25(1 Suppl):3-14. 